\title{
Looking at the job first
}

In Nature last November, Cyril Cooper of the Institution of Professional Civil Servants highlighted the discontent among UK Civil Service scientists, and argued that it stemmed largely from differences they experience in salary and career progression compared with graduate administrators. David Budworth of the Confederation of British Industry replies.

The NEWS that the Expenditure Committee is to examine the progress made in implementing the 1968 Fulton Report on the Civil Service is indeed welcome. Although the stimulus has no doubt been the rising public indignation at the advantages in terms of pay, security, and perhaps most conspicuously pensions that civil servants enjoy, the terms of reference of the investigation seem likely to be sufficiently wide to permit the Committee to tackle the problem of civil service scientists, which has been consistently ducked in recent years.

While it may well be good trade union tactics to argue, as Cyril Cooper does (November 20, 1975, page 186) that the scientific civil service is really just an ordinary part of the higher reaches of the service and should be treated as such, this approach flies in the face of economic reality and common sense. It is certainly also in flat contradiction of the Fulton principle of "look at the iob first". Regrettably perhaps, but undeniably, the number of jobs available for administrators in the civil service has increased, and with it the security and career prospects of the incumbents, in our developing welfare state in which authority is looked upon to solve all the problems.

Science having conspicuously failed in its overblown claims to solve these problems, the opportunities for scientists have not expanded in a similar way. As David Davies has reminded us (May 22, 1975, pages 293-296), the scientific civil service has been static in numbers for the best part of twentyfive years, and it suffers from considerable internal embarrassments caused by its over-concentration of older scientists. Yet these under-used and probably unhappy people are a considerable national resource of talent and experience. Diverting them to supposedly useful tasks in their present locations is unlikely to do much of value. They must be moved out to contribute to solving our national problems in the places where it is increasingly being recognised that something effective can be done: industry and the schools.

A Select Committee such as the Expenditure Committee is perhaps the only type of body which can look at these problems relatively free from civil service establishment influence. The Fulton Committee itself brushed aside the suggestions made to it, significantly including some from inside the service itself, that the scientific civil service would benefit from not being a career service; and Lord Rothschild's forthright comments on the immobility of scientific civil ser vants were safely defused by the terms of reference given to the Bondi task force which was set up to tackle the problem. and of its chairman, whose personal commitment to mobility has been amply proved by deeds as well as words, that it did manage to rise slightly above its terms of reference and record its view that permanent moves were, in the end, more important than the immensely difficult and therefore marginally effective secondments to which it was nominally confined. Ironically perhaps, the work so far of the interchange unit set up in the Civil Service Department to keep the flame of scientific mobility alive, seems to have proved the critics of civil service privileges right, for the movement into the service has greatly exceeded the movement out.

Of course, as is apparent from Cyril Cooper's article, all pretence that the "fair comparison with outside employment" system for determining pay applies to civil service scientists has been abandoned, following the report of the late Pay Board's Advisory Report No. 3 of April 1974. This body again tamely accepted that something closely approximating to parity should exist between specific grades in the
It is greatly to the credit of that body administration and scientific groups of the service.

The reforms in the scientific civil service which are needed to effect a long-term cure are fairly clear in outline, and have been put forward so often that there is no need to repeat them here; but what of the short and medium term? We cannot afford to wait another 30 years or so, even assuming that the necessary changes are made, for the situation to right itself. Something must be done before that, and preferably soon. The former Department of Trade and Industry admitted in a burst of frankness in 1972 that it wanted to reduce the burden that its laboratories placed on public expenditure, but its attempts to do so by selling contract research cannot have made much impact. The unproductive PSOs mentioned by David Davies can hardly be declared redundant, particularly with unemployment at its present levels; but could not some way he found of getting them out to somewhere where their undoubted abilities might be put to use? From all accounts, good quality scientists and mathematicians are still not coming forward for teaching posts, and even when they do it seems that local authorities cannot afford to pay them. Is it totally beyond the wit of what is supposed to be the best administrative civil service in the world to devise some methods of utilising those on the public payroll to do the jobs which need to be done?

Again, if the Government is serious in its commitment to putting the needs of manufacturing industry above almost all other calls on its resources, there will be a need to move morc brain power, and to move it pretty quickly, to where it can be commercially effective. Some scientists in government laboratories have proved themselves to be effective in marketing their services. Perhaps they could be equally useful in marketing the mechanical engineering and other products by which we live. Or will the real gap in our country, that between those who live on taxpayers' money by the skilled deployment of political argument, and those who live by exploiting their entrepreneurial abilities in some kind of market, be allowed to get even worse, so that we all eventually starve? 